\title{
The Action of the Digestive Enzymes of the Garp
}

\author{
BY A. BONDI AND A. SPANDORF \\ Animal Nutrition Laboratory, Agricultural Research Station, Rehovoth, Israel
}

(Received 10 December 1953)

\begin{abstract}
The intensive breeding of carp in Israel involves large numbers of fish in small fish ponds and necessitates the use of large amounts of feeding-stuffs as food supplements. Data on the utilization of the various feeds by the carp (Cyprinus carpio) are, therefore, of great importance. Experiments were consequently undertaken to investigate the enzymic action of the digestive juices of the fish. The digestive system of the carp is distinctly different from those of other animals since the carp lacks a stomach. The mode of action of the digestive juices of this fish is, therefore, of special interest. The rate of digestion of various foods by the digestive juices of the carp can also serve as a measure of the value of such foods for this species. Previous work done in this field is very limited (Vonk, 1927; Schlottke, 1939).
\end{abstract}

\section{EXPERIMEN'TAL}

Scope of the work. In this work pancreatic and intestinal extracts were incubated with the following: (I) a purified protein, casein, (2) peptone, a partly hydrolysed protein prepared by laboratory methods, (3) meat meal, (4) fish meal, (5) soya-bean meal, (6) peanut meal, (7) starch, (8) maltose, and (9) wheat bran. The $\mathrm{pH}$ of the medium was between $7^{\circ} 0$ and $8 \cdot 2$, which are the limits of the $\mathrm{pH}$ values found by Vonk (1927) in the contents of the carp's intestine. At specified time intervals, the amounts of digestion products (amino-acids or sugars) were determined. In some instances, the effects of changes in the concentration of the pancreatic or intestinal extracts, or in temperature, or in $\mathrm{pH}$, on the rate of digestion of the various foods were investigated.

Preparation of pancreatic and intestinal extracts. The method of Wundsch (1927) was followed. From ten carp of average weight $350 \mathrm{~g}$, $100 \mathrm{~g}$ pancreatic tissue were obtained. The tissue was partly dried on filter-paper and cut into small pieces. The material was then homogenized in a Waring blendor with the gradual addition of I $50 \mathrm{ml}$. of $30 \%(\mathrm{v} / \mathrm{v})$ ethanol. The mixture was left for $48 \mathrm{~h}$ in a refrigerator and shaken from time to time. It was then filtered through cloth and brought to $\mathrm{pH}_{7}$ with $2 \mathrm{~N}-\mathrm{KOH}$, thymol blue being used as indicator. The final volume obtained was roo $\mathrm{ml}$.

The intestinal extract was prepared in the same manner from ten carp. The final volume of the extract was $75 \mathrm{ml}$. from $40 \mathrm{~g}$ intestinal tissue.

Incubation procedure. A specified quantity of the material to be tested ( $3 \mathrm{~g}$ casein or peptone or $6 \mathrm{~g}$ ether-extracted protein foods, or starch solutions containing $\mathrm{I} \cdot 5 \mathrm{~g}$ starch) was placed in a $250 \mathrm{ml}$. Erlenmeyer flask. Fifty $\mathrm{ml}$. of buffer solution and the 
required amount of pancreatic or intestinal extract were added, and the volume was then brought to $150 \mathrm{ml}$. with $0.067 \mathrm{M}$-phosphate buffer solution. Several drops of toluene were added and the flask was placed in an incubator and periodically shaken. Samples of 5 or $10 \mathrm{ml}$. were taken at specified time intervals for the determination of products of digestion. In the protein-digestion experiments free amino-acids were measured (carboxyl groups according to Sørensen (1907), or amino-groups according to Pope \& Stevens (1939)). In the experiments with carbohydrates of high molecular weight (starch), the quantity of reducing sugar liberated was determined according to Lehmann-Maquenne's (1932) modification of the Bertrand method. Digestion was considered to be complete when the quantity of liberated products of digestion did not increase from one determination to the next. Acid hydrolysis by boiling in strong acid for $20 \mathrm{~h}$ gave values for the calculation of percentage digestion by the digestive juices. The amount of amino-acid liberated by acid digestion is the maximum that can be obtained from various foodstuffs and can therefore be considered as $100 \%$.

\section{RESULTS}

\section{Protein-digestion experiments}

Digestion of casein. The results of the experiments on the breakdown of casein by pancreatic extract are given in Figs. I and 2 which show that the digestion of casein with pancreatic extract, under varying conditions, resulted in a $50 \%$ breakdown. Fig. I shows that raising the temperature of digestion mixture from 25 to $38^{\circ}$ caused a marked increase in the digestion rate (Exps. I and 2). Doubling the quantity of pancreatic extract resulted in more rapid breakdown of casein at the beginning of the incubation. At the end of the experiment, however, no difference was observed if 6 or $12 \mathrm{ml}$. of pancreatic extract were incubated with $3 \mathrm{~g}$ casein (Fig. I, Exps. 2 and 3 ). In both instances the digestion reached $50 \%$ at $38^{\circ}$ and at $\mathrm{pH} 7 \cdot 0$. A comparison of Exps. 2 and 4 (Fig. I) shows that a change in $\mathrm{pH}$ from $7 \cdot 0$ to 8.2 retarded the digestion. In Exp. 5 (Fig. 2) a study of the action during the first hours after the addition of the enzyme to the substrate showed that the rate of digestion was comparatively high during the first hours.

The casein was digested to a small extent only by intestinal extract (Exp. 6). On the other hand, the rate of digestion and the proportion digested were much higher when pancreatic extract and intestinal extract were used together. Pancreatic extract broke down about $40 \%$ of the casein, intestinal extract only $12 \%$, and both together up to $82 \%$ (Fig. 2). This increase in the rate and extent of the digestion of casein might well be caused by the presence of an activator of pancreatic digestion in the intestinal extracts, as with enterokinase in mammals.

Digestion of peptone. The results are given in Fig. 3. Peptone is the only protein product investigated in these experiments that was digested to a greater extent by intestinal extract than by pancreatic extract ( $6_{3}$ as against $26 \%$ ). It is well known that the intestinal enzymes of other animals are more suitable for the breakdown of compounds of medium molecular weight such as peptone than for the breakdown of the unchanged food proteins. Pancreatic extract, on the other hand, is mainly active 


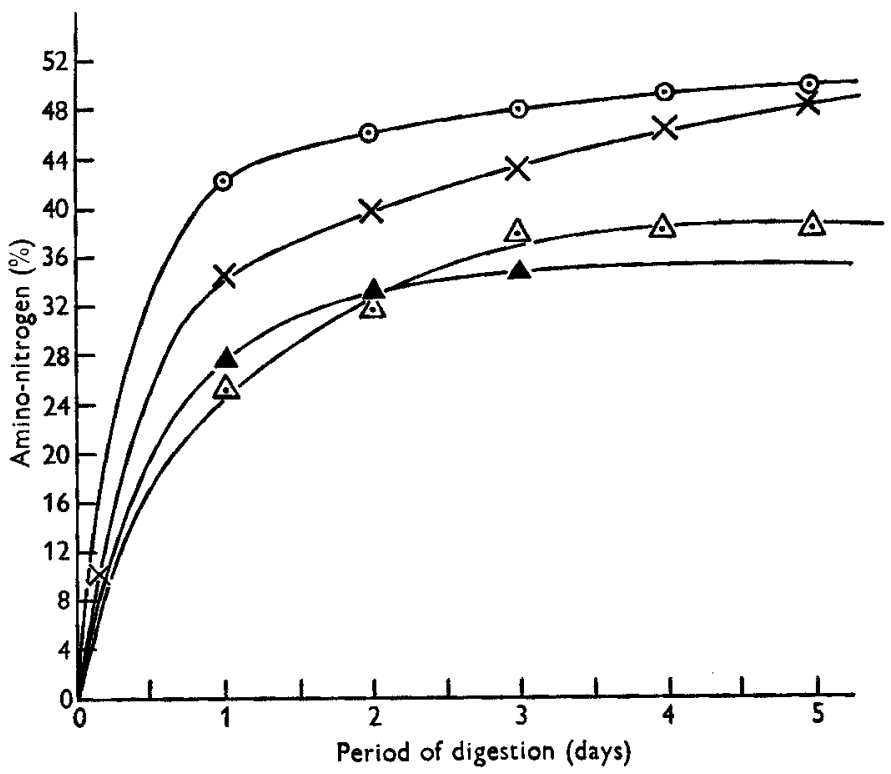

Fig. I. Percentage of amino-nitrogen liberated in the digestion of casein by pancreatic extract of carp (the amino-nitrogen liberated by acid hydrolysis of casein is taken as roo\%). $\Delta$, Exp. I, $6 \mathrm{ml}$. extract, temperature $25^{\circ}, \mathrm{pH} 7{ }^{\circ} 0 ; \times$, Exp. $2,6 \mathrm{ml}$. extract, temperature $3^{\circ}, \mathrm{pH} 7{ }^{\circ} \circ ; \odot$, Exp. 3 , $12 \mathrm{ml}$. extract, temperature $38^{\circ}, \mathrm{pH} 7 \cdot 0 ; \Delta$, Exp. 4, $6 \mathrm{ml}$. extract, temperature $38^{\circ}, \mathrm{pH} 8 \cdot 2$.

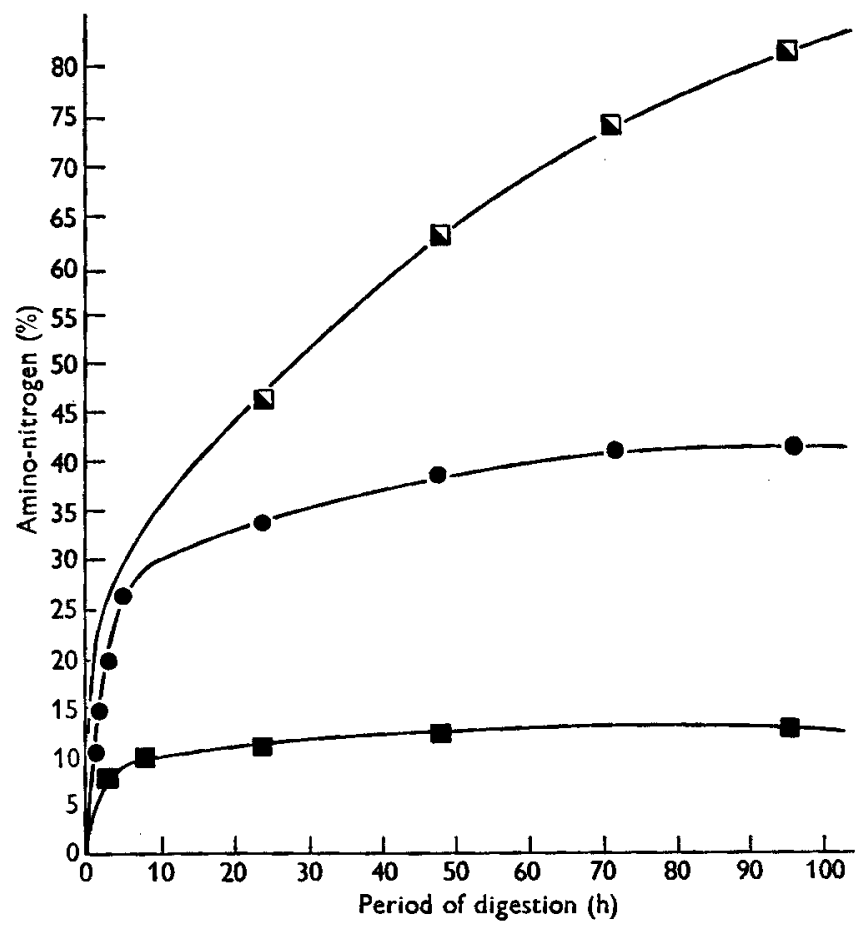

Fig. 2. Percentage of amino-nitrogen liberated in the digestion of casein by pancreatic and intestinal extracts of the carp, at $\mathrm{pH} 8 \cdot 2$, temperature $38^{\circ}$ (the amino-nitrogen liberated by acid hydrolysis of casein is taken as $100 \%$ ). O, Exp. 5, $12 \mathrm{ml}$. pancreatic extract; $\mathbf{0}$, Exp. 6, 10 ml. intestinal extract; $\nabla$, Exp. 7, $5 \mathrm{ml}$. pancreatic extract and $5 \mathrm{ml}$. intestinal extract. 
on native proteins and its activity is greatly decreased when products of partial hydrolysis, such as peptone, are used as substrate. Pancreatic and intestinal extracts together substantially increased the initial speed of peptone digestion, possibly owing to the presence of an activator in the intestinal juice. However, the amount of aminonitrogen ultimately liberated by the mixture of pancreatic and intestinal juices was the same as that formed by the action of intestinal juice alone (Fig. 3).

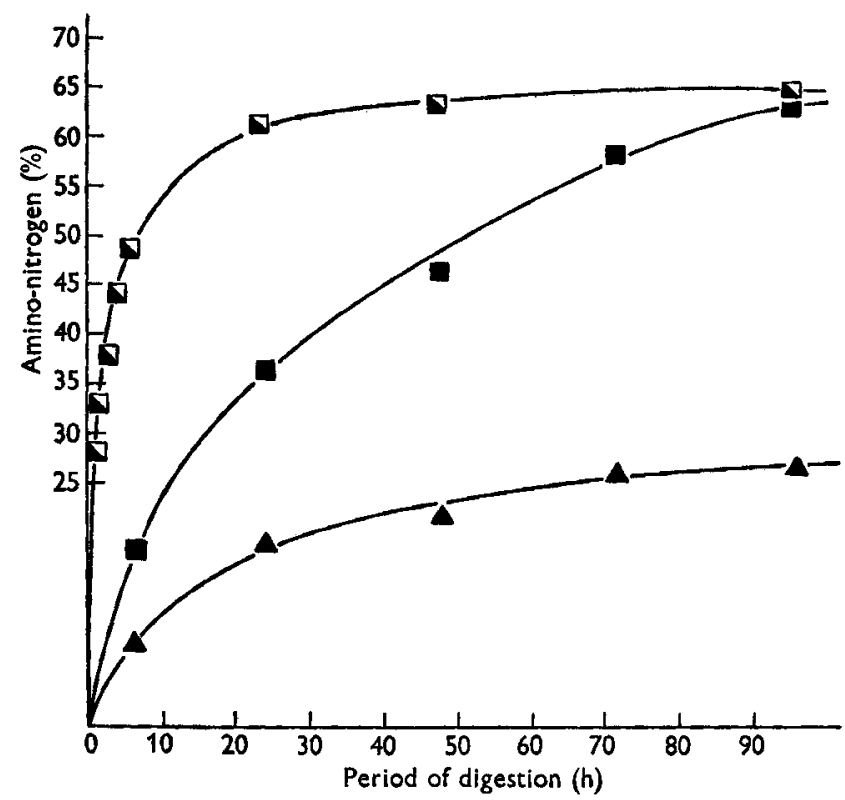

Fig. 3. Percentage of amino-nitrogen liberated in the digestion of peptone by pancreatic and intestinal extracts of the carp at $\mathrm{pH} 8.0$, temperature $38^{\circ}$ (the amino-nitrogen liberated by acid hydrolysis of peptone is taken as $100 \%$ ). $\Delta$, Exp. 8, $5 \mathrm{ml}$. pancreatic extract; $\mathbf{m}$, Exp. 9, ro ml. intestinal extract; $\nabla$, Exp. I0, $5 \mathrm{ml}$. pancreatic extract and $5 \mathrm{ml}$. intestinal extract.

Pancreatic digestion of foodstuffs. Experiments on the digestion of soya-bean meal, peanut meal, meat meal, and fish meal by pancreatic extracts were conducted under very similar conditions. The results show that the rate and extent of the digestion of these substrates were very similar to those noted in the digestion of casein. Of the terminal groups obtainable by acid hydrolysis $30-35 \%$ were liberated from these foodstuffs after $24 \mathrm{~h}$ incubation at $\mathrm{pH} 7 \cdot 0$.

\section{Digestion of carbohydrates}

Starch is a major constituent of most carbohydrate foods such as bran and grain. Special attention was therefore paid to the breakdown of this carbohydrate by the digestive extracts of the carp. The breakdown was almost quantitative at $\mathrm{pH} 7 \cdot 0$ in $24 \mathrm{~h}$ both at $25^{\circ}$ and at $38^{\circ}$. The rate of digestion decreased slightly when the experiment was carried out at $\mathrm{pH} 8 \cdot 2$ instead of $7^{\circ} \circ$ (Fig. 4).

The calculation of the degree of starch breakdown in Exps. II-I4 was made on the assumption that the starch is hydrolysed to glucose without any decrease in rate at 
the intermediate stage of maltose. This assumption is justified by the results of Exps. I5-18 (Fig. 5), in which pancreatic extract was added to maltose and to starch under identical conditions. The maltose was hydrolysed much more rapidly than the starch. It may be concluded, therefore, that starch hydrolysis does not stop at the intermediate stage of maltose.

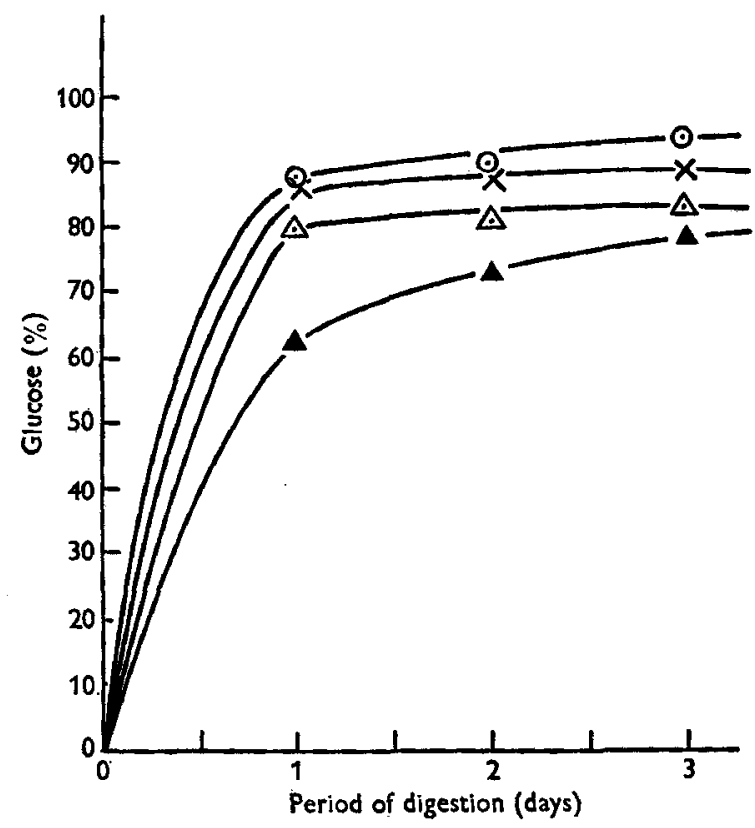

Fig. 4. Percentage of glucose liberated in the digestion of starch by pancreatic extract of the carp (the glucose liberated by acid hydrolysis of starch is taken as $100 \%$ ). $\triangle$, Exp. II, $6 \mathrm{ml}$. extract, temperature $25^{\circ}, \mathrm{pH} 7 \cdot 0 ; \times$, Exp. 12, 6 ml. extract, temperature $38^{\circ}, \mathrm{pH} 7 \cdot 0 ; \odot$, Exp. 13, I2 ml. extract, temperature $38^{\circ}, \mathrm{pH} 77^{\circ} ; \Delta$, Exp. $14,6 \mathrm{ml}$. extract, temperature $3^{\circ}, \mathrm{pH} 8 \cdot 2$.

The action of pancreatic extract on bran was also investigated; the starch of the bran was more slowly digested than the pure starch solution, owing perhaps to its being in suspension and not in solution. Under suitable experimental conditions (longer time intervals, the presence of sufficient pancreatic extract), however, the total percentage digestion approached that of pure starch solution.

Experiments on the action of intestinal extract on starch solutions showed that no reducing sugar was liberated. The intestinal extract, therefore, did not contain any amylolytic enzymes, but maltose was slowly digested by the intestinal extract to the extent of $30 \%$ after 3 days.

\section{DISCUSSION}

Since the digestive juices of the carp are apparently capable of digesting proteins and carbohydrates of various types, it is understandable that the carp can digest these different foodstuffs to an appreciable extent in spite of the lack of a stomach.

The enzymic activity of the digestive juices of the carp is very similar to that of the corresponding digestive juices of mammals. Pancreatic extracts from the carp like 
those from mammals, contain enzymes that effect the breakdown of protein and starch to a considerable extent. The intestinal extract of the carp attacks mainly partly hydrolysed proteins of the peptone type and its action on native protein or starch is very limited; as is well known, the intestinal juice of mammals possesses appreciable

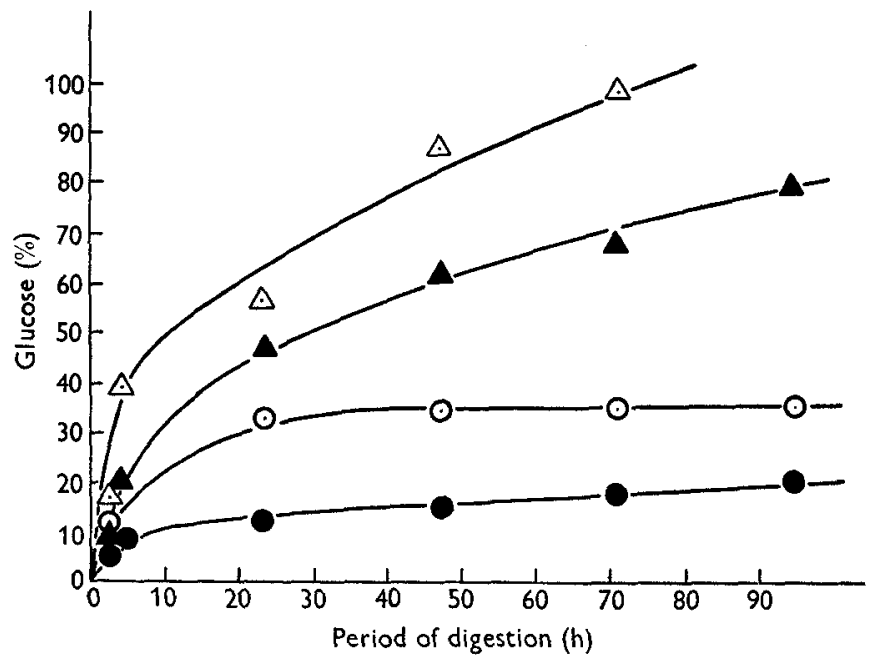

Fig. 5. Percentage of glucose liberated in the digestion of starch and maltose by $4 \mathrm{ml}$. pancreatic extract of the carp at $\mathrm{pH} \mathrm{8.2,} \mathrm{temperature} 17^{\circ}$ (the glucose liberated by acid hydrolysis of starch and maltose is taken as $100 \%$ ). $\triangle$, Exp. $15,1 \cdot 5 \mathrm{~g}$ maltose; $\odot$, Exp. r6, r.5 g starch; $\Delta$, Exp. I7, 3.0 g maltose; 0 , Exp. 18, 3. g starch.

action on peptides. The digestion of protein by carp pancreatic extract is markedly increased by the addition of intestinal extract. This is possibly due to the presence in the intestinal juice of an activator similar to enterokinase in the mammals.

In the carp the pancreatic juice has much greater maltase activity than has the intestinal juice, whereas in mammals the opposite is true.

\section{SUMMARY}

I. Casein, meat meal, fish meal, peanut meal and soya-bean meal were digested appreciably by pancreatic extracts from the carp.

2. Intestinal extracts of the carp digested casein to a small extent only.

3. The rate and extent of casein digestion by carp pancreatic extracts were raised markedly by the simultaneous action of intestinal extract.

4. Peptone was digested by pancreatic extract to a small extent only and by intestinal extract to a much greater degree.

5. Maltose, starch and bran were digested by pancreatic juice without difficulty.

6. Starch and bran were not attacked at all by intestinal juice, which hydrolysed maltose to a very small extent. 
REFERENCES

Lehmann-Maquenne, in G. Klein (1932). Handbuch der Pflanzenanalyse, Vol. 2, p. 786 . Wien: Julius Springer.

Pope, C. G. \& Stevens, M. F. (1939). Biochem. F. 33, 1070.

Schlottke, E. (1939). S.B. naturf. Ges. Rostock, 7, 27. See also Chem. Abstr. (1942). 36, 6673.

Sørensen, S. P. L. (1907). Biochem. Z. 7, 45.

Vonk, H. J. (1927). Z. vergl. Physiol. 5, 445.

Wundsch, W. (1927). Die Arbeitsmethoden der Fischereibiologie. Berlin-Wien: Urban und Schwarzenberg.

\title{
Effect of Feeding Aureomycin to Calves upon the Establishment of their Normal Rumen Microflora and Microfauna
}

\author{
By S. O. MANN, FRANCES M. MASSON AND A. E. OXFORD \\ Rowett Research Institute, Bucksburn, Aberdeenshire
}

(Received I7 December 1953)

American experience (summarized by Knodt, I953) is overwhelmingly in favour of the view that daily feeding of small amounts of aureomycin to calves, from about the Ioth to the I2oth day of age, markedly increases their appetite, growth rate and general well-being. It is during this period of its life that the calf gradually becomes a multi-stomached animal with development of a dense and characteristic population of living micro-organisms in its rumen, reticulum and omasum. It is known that the antibiotic in question, aureomycin, has certain well-marked properties which differentiate it from, for example, penicillin and streptomycin, namely:

(a) Wide bacteriostatic (not bactericidal) powers, inhibiting nearly all bacteria, Gram positive as well as Gram negative, although, as usual, cocci are the most sensitive bacteria (Paine, Collins \& Finland, I948), the few exceptions to this rule being aerobes such as Pseudomonas and Proteus which normally do not flourish in an anaerobic environment like the rumen.

(b) No marked power of inducing the formation of antibiotic-resistant strains of bacteria; in this respect it is unlike streptomycin.

(c) Inability to induce the formation of an 'aureomycinase' in any bacterial species.

(d) Maximum chemical stability well on the acid side of neutrality (Schneierson \& Toharsky, 1949); in this respect as in the last it is unlike penicillin.

(e) Power of inhibiting protein synthesis by bacteria at an extremely small concentration without inhibiting the processes of fermentation (Gale \& Folkes, 1953).

It might therefore be expected that the feeding of aureomycin from an early stage would exert some characteristic effect upon the establishment of the normal adult microbial population of the rumen. This effect might be either to delay its full appearance, or to change its composition both as regards density of population and the relative numbers of the different kinds of bacteria represented. This argument supposes, however, that a sufficiently high concentration of aureomycin is built up 